\title{
Manipulando formas e tecidos
}

Juggling Forms and Fabrics

\section{Camila Puccini}

Pós-Graduanda em Modelagem do Vestuário da Universidade Feevale camilacpuccini@gmail.com

\section{Julia Isoppo Picoli}




\section{Manipulando formas e tecidos}

Juggling Forms and Fabrics

Camila Puccini e Julia Isoppo Picoli

\section{Resumo}

O presente trabalho se propõe a comparar quatro metodologias que têm como foco a manipulação de diferentes formas e tecidos, a fim de gerar alternativas e soluções mais criativas para o mercado atual, podendo ser aplicadas durante a elaboração do produto ou na peça final. A operacionalização do presente estudo foi realizada durante a disciplina de Manipulação da Forma na turma de PósGraduação em Modelagem do Vestuário da Universidade Feevale, no ano de 2015. As metodologias trabalhadas foram: Singer (2013), Rutzky e Palmer (2011) e Roberts (2013). Também foi realizado um exercício que consiste em uma junção de técnicas, proposto pela professora da disciplina. Para tanto, buscou-se verificar os diferenciais entre cada método e as especificidades da matéria prima utilizada. O objetivo final da disciplina consiste na aplicação de três técnicas ensinadas em aula na confecção de uma peça. Cada metodologia atingiu resultados inesperados focados em diferentes nichos como comercial e conceitual.

Palavras- chave: Manipulação da forma; Forma conceito; Comparação de metodologia

\begin{abstract}
This study aims to compare four methods which focuses on the manipulation of different shapes and fabrics. In order to generate alternative and more creative solutions to the current market and can be applied during the preparation of the product or the final piece. The operationalization of this study was performed in the discipline "shape manipulation" of the Drafiting MBA Class at the Feevale University in the year 2015. The methods worked were: Singer (2013), Rutzky and Palmer (2011) and Roberts (2013). In addition to these it was also carried out an exercise consisting of an amalgamation of techniques passed on by the teacher of the discipline. To this end, it sought to verify the differences between each method and the raw material used. The ultimate goal of discipline is the development of a piece that use at least three techniques taught. Each methodology has reached unexpected results focused on different niches such as commercial and conceptual.
\end{abstract}

Keywords: Manipulation of form; Concept form; Comparison methodology. 


\section{Introdução}

A modelagem pode ser dividida em duas classificações chamadas de drafiting ou draping. A técnica do drafiting tem como princípio o traçado da modelagem em uma superfície plana, podendo ser ela papel ou tecido, a partir de medidas retiradas do corpo humano ou manequim. Já o draping ou moulage, consiste em experimentos com tecido diretamente sob o corpo humano ou manequim (OSÓRIO, 2007).

Ferreira (2013) considera que no processo de desenvolvimento do vestuário, deve-se respeitar a anatomia do corpo humano e os fatores anatômicos e ergonômicos. Podendo se utilizar de estudos da geometria, mais conhecida como modelagem plana ou modelagem em "2D”, adaptada para as formas tridimensionais/volumétricas. Sendo possível também utilização da moulage, que permite realizar formas desejadas ou inesperadas. A matéria-prima utilizada pode assumir formas em constante mutação, gerando resultados únicos.

Para Heinrich (2007) a modelagem parte do princípio da análise do corpo humano, levando em consideração a função da peça, a atividade exercida, o movimento dos músculos e das articulações. Já Löbach (2000 apud SILVEIRA, 2008) considera que a modelagem e o material utilizado para confecção são a essência do produto, e resultam em um tipo de caimento, alinhamento ao corpo, e sensação de bem-estar. Levando em consideração as três possíveis funções de um produto: prática, simbólica e estética.

O objetivo da presente pesquisa é estudar algumas técnicas de manipulação do tecido e seus efeitos em cada matéria prima. Bem como, realizar um comparativo dos métodos e resultados obtidos. Para tanto, buscou-se analisar: (a) os diferenciais entre cada método; (b) resultados na matéria prima utilizada. A operacionalização do presente estudo foi realizada durante a disciplina de Manipulação da Forma na turma de PósGraduação em Modelagem do Vestuário da Universidade Feevale, no ano de 2015.

\section{Metodologias e processos}

Como mencionado na introdução deste trabalho, foram utilizadas quatro metodologias - Singer (2013), Rutzky e Palmer (2011), Roberts (2013) e a quarta consiste em uma junção de técnicas desenvolvida e repassada pela professora da disciplina. Estas foram trabalhadas devido a escolha da professora orientadora da 
disciplina de Manipulação da Forma, Julia Isoppo Picoli. O processo ocorreu através de evolução nas técnicas ensinadas em três aulas com objetivos diferentes. O objetivo final da disciplina consiste na elaboração de uma peça que tenha a utilização de no mínimo três técnicas ensinadas.

As primeiras técnicas demonstradas em aula foram baseadas nos autores Singer (2013) com o livro "Fabric Manipulation - 150 creative sewing techniques” e Rutzky e Palmer (2011) com o livro "Shadowfolds - Surprisingly Easy-to-make geometric designs in fabrics", em que a essência das técnicas é o origami de tecido. Dentre os vários exemplos a serem explorados, foram confeccionados três modelos da metodologia de Singer (2013) e dois modelos da metodologia de Rutzky e Palmer (2011).

Singer (2013) demonstra os mais distintos tipos de dobraduras, franzidos, pregas, babados, nesgas, nervuras, e demais costuras diferenciadas com ou sem volume. Foram confeccionadas duas dobraduras em tecidos como gorgulinho (48\% CO / 52 PES - na cor roxa) e cetim Audrey (80\% PES / 20\% PUE - cor marrom), realizando um comparativo entre o comportamento do tecido ao sofrer a dobra e entrar em contato com o calor do ferro. Ademais foram confeccionadas pregas simples com costuras geométricas aplicadas. Os exercícios com modelos do livro podem ser visualizados na figura 1. 
Figura 1 - Exercícios segundo Singer (2013)

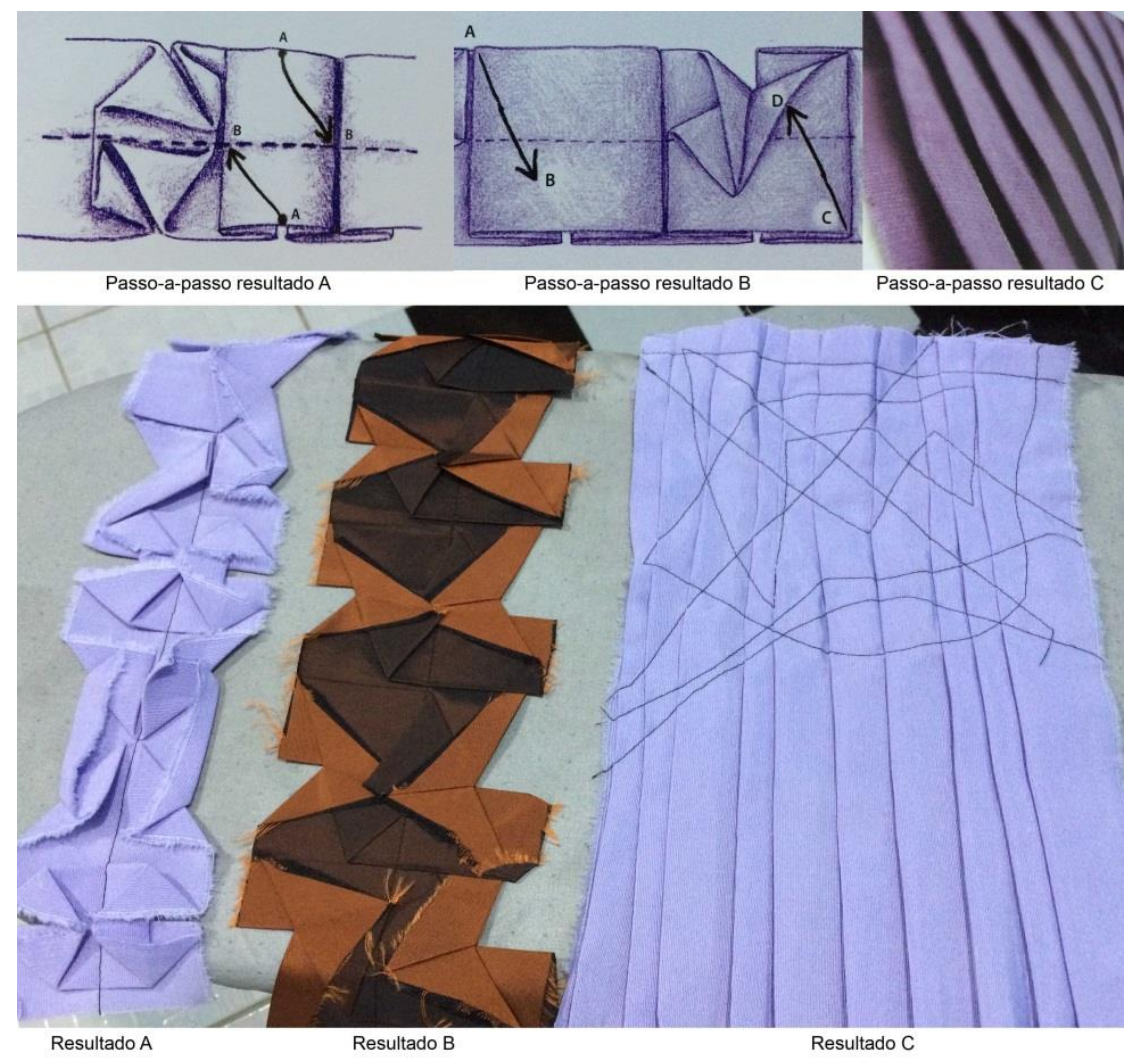

Fonte: Elaborado pela autora.

Rutzky e Palmer (2011) demonstram diversos tipos de origamis em algodão cru, onde a dobra acontece através de pontos simples de costura manual entre os pontos do molde. Todos os modelos são apresentados com uma pequena explicação da confecção e molde para ampliar e reproduzir. A maioria apresenta imagens do processo produtivo e do resultado obtido. Foram confeccionados dois exemplos, sendo eles: "Fujimoto's twits" que consiste em uma forma circular com octógonos, retângulos e linhas e o "Scales divider screen" com a forma básica de triângulos e linhas. Os exercícios com modelos do livro foram confeccionados em tecido de Algodão Cru (100\% CO) e podem ser visualizados na figura 2. 
Figura 2 - Exercícios segundo Rutzky e Palmer (2011)

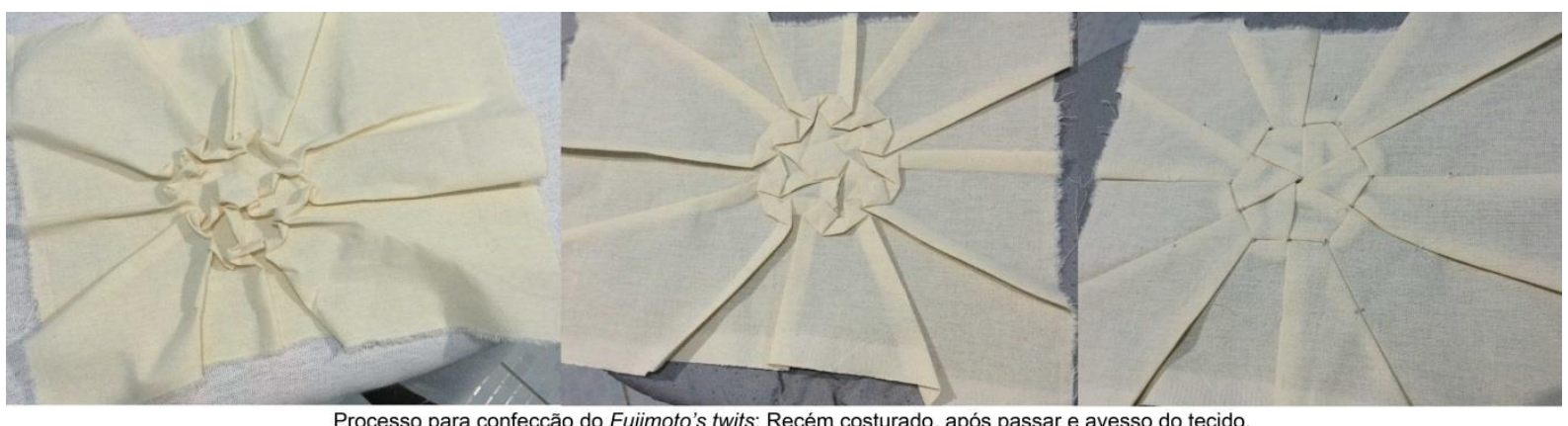

Processo para confecção do Fujimoto's twits: Recém costurado, após passar e avesso do tecido.

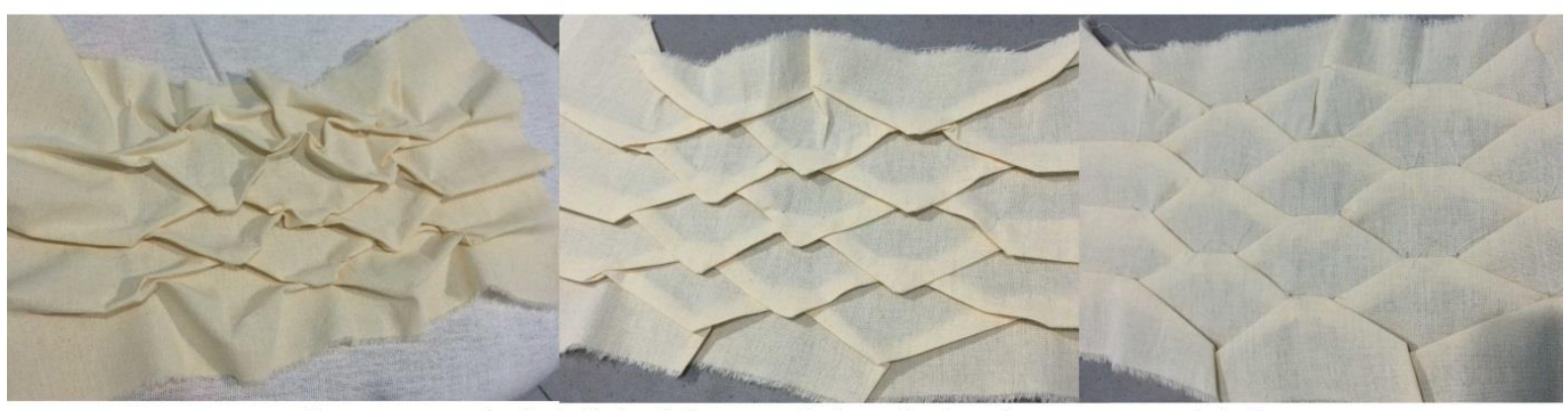

Processo para confecção do Scales divider screen: Recém costurado, após passar e avesso do tecido.

Fonte: Elaborado pela autora.

$\mathrm{Na}$ segunda aula realizou-se um estudo de formas e volumes em tecido plano a partir de uma junção de técnicas e metodologias transmitidas pela professora Julia Isoppo Picoli. A técnica consiste em confeccionar o bloco básico de uma blusa frente e costas, fechando pences, ombros e laterais. A seguir elaboraram-se desenhos geométricos ou orgânicos de formas variadas ao longo da peça, utilizando marcações de números ou letras ao longo das formas. Estas devem ser recortadas, extraídas da blusa e redesenhadas em papel mantendo a numeração do tecido. Após, deve-se realizar aberturas nos moldes, dando o maior volume possível ou desejado. Finalizado esse processo, recortam-se novamente as peças em tecido e as replicam-se na blusa de acordo com as marcações iniciais. Pode-se cumprir a manipulação do tecido antes da etapa de costura final, criando diferentes pregas, pontos, franzidos ou piques. O resultado deste experimento foi confeccionado em Algodão (100\% CO), e pode ser visualizado na figura 3. 
Figura 3 - Exercícios segundo técnicas da professora Julia Isoppo Pico

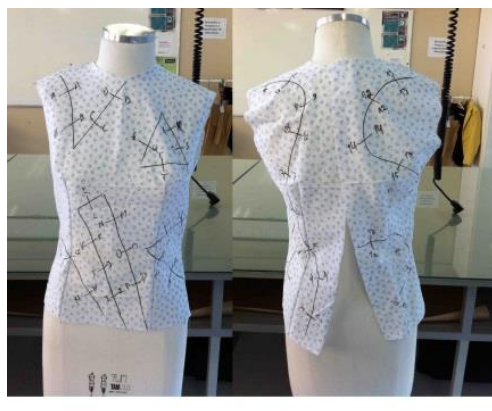

Etapa 1: Desenhar formas do bloco básico da blusa

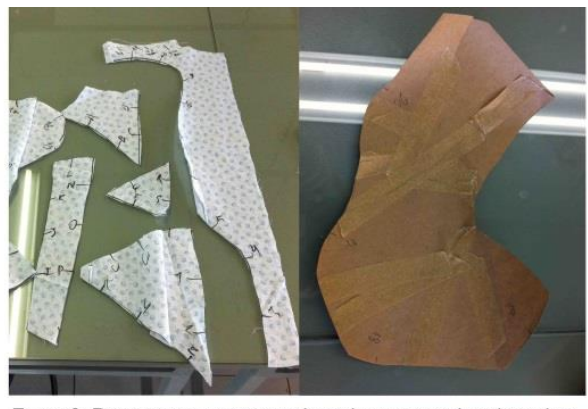

Etapa 2: Recortar as partes e redesenhar no papel, redesenhar no papel, realizar cortes e aumentar a dimensão do molde

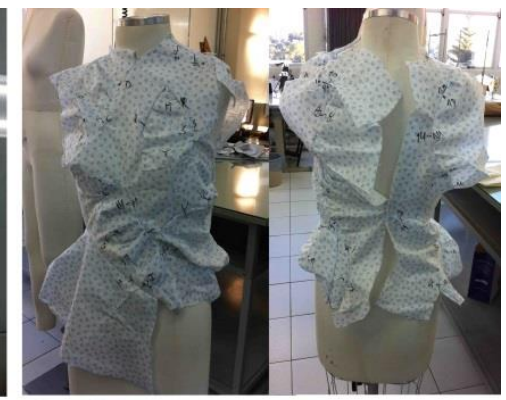

Etapa 3: Recortar os moldes aumentados no tecido alfinetar, costurar e manipular
and

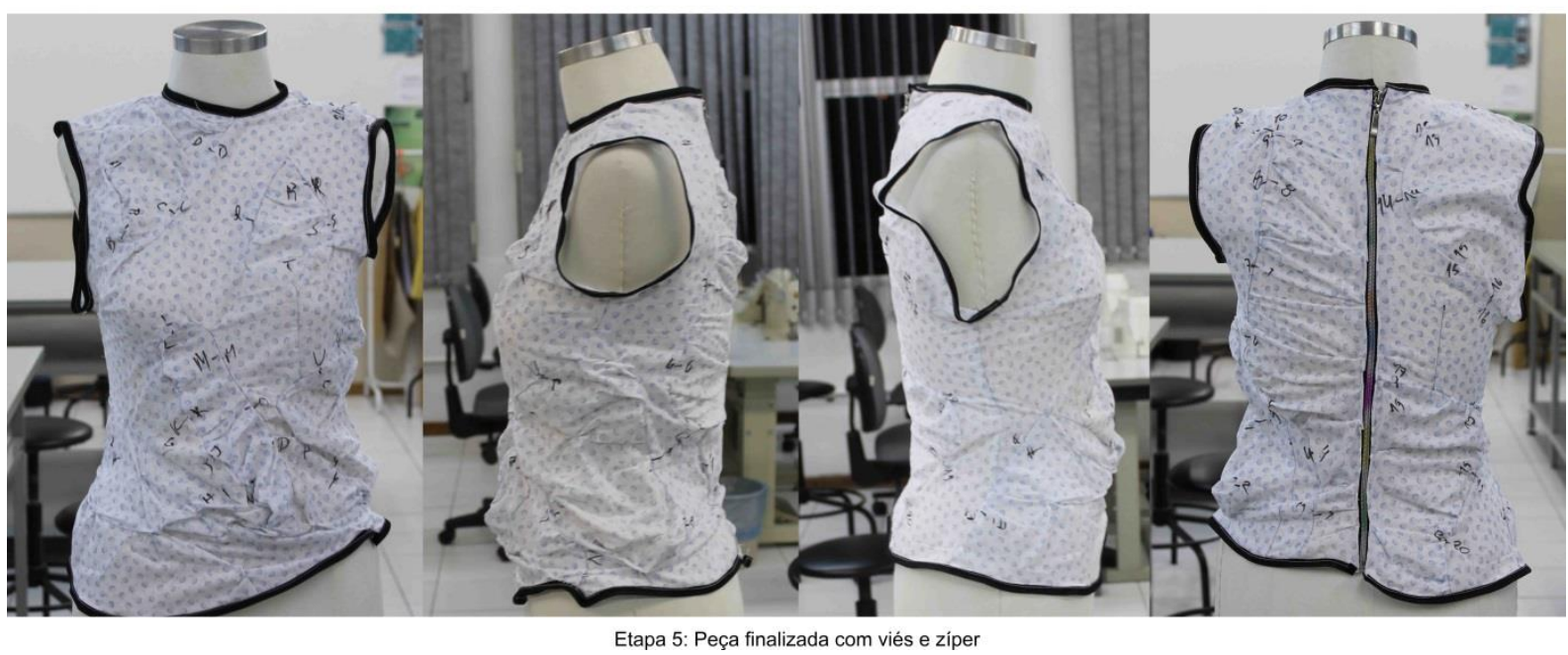

Fonte: Elaborado pela autora.

O terceiro e último estudo realizado em aula envolveu a manipulação de formas e volumes, porém com foco em malharia circular, utilizando como base a metodologia de Roberts (2013) o "Free Cutting”. Foram realizados dois exercícios que derivam da técnica, o primeiro nomeado de "Tunnel" consiste em costurar um retângulo de maneira que forme um tubo, dobrar de forma aleatória e cortar círculos que podem gerar novas formas ou que será habitado por alguma parte do corpo (pescoço, cava, cintura), confeccionado em malha tubular (90\% PA, $10 \%$ PUE). O segundo exercício é nomeado de "Plug" e utiliza o conceito de encaixar formas diferentes, umas dentro das outras, criando um volume não usual. Por exemplo, desenhar um retângulo, medir o tamanho da margem desta forma e desenhar um círculo com a mesma medida, após recortar o retângulo e encaixar o círculo no lugar gerando um volume diferente. Para a peça confeccionada foram utilizados malha circular (90\% CO, 10\% PUE) e tecido plano, a partir do foco em reaproveitamento e mistura de gramaturas de tecidos. O resultado destes experimentos pode ser visualizado nas figuras 4 e 5 . 
Figura 4 - Exercícios Tunnel segundo Roberts (2013)

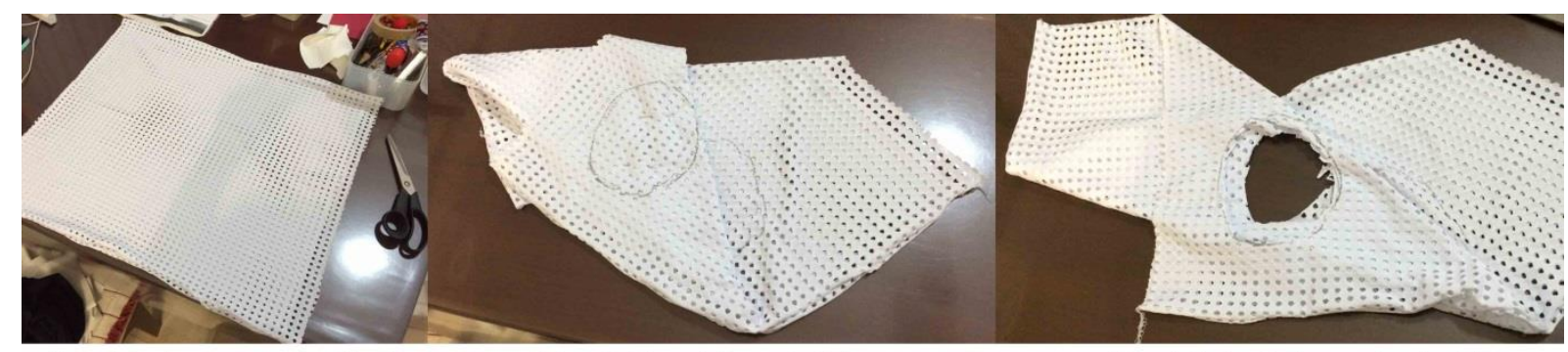

Etapa 1: Costurar um grande retângulo Etapa 2: dobrar de forma aleatória

Etapa 3: Cortar círculos em cima das dobras
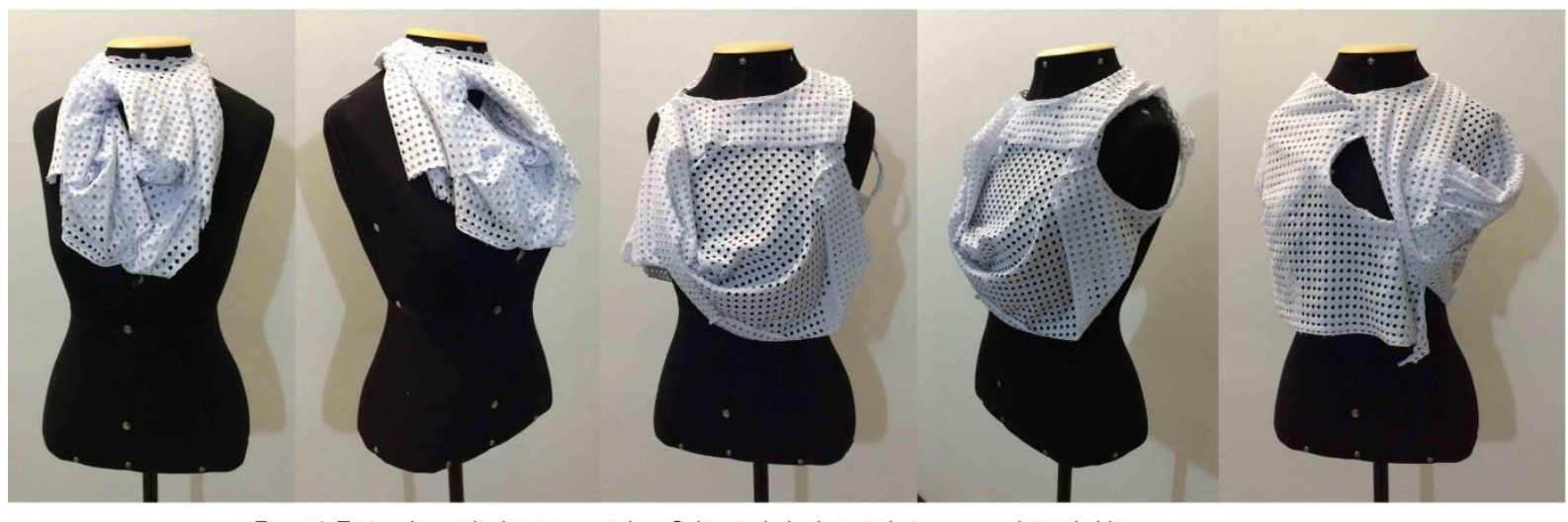

Etapa 4: Testes do resultado no manequim - Gola com babados e volume para projetos de blusas

Fonte: Elaborado pela autora.

Figura 5 - Exercícios Plug segundo Roberts (2013)

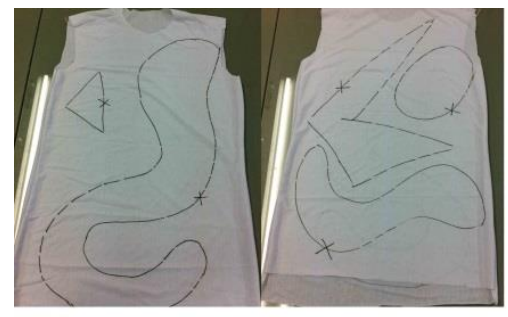

Etapa 1: riscar formas geométricas e orgânicas

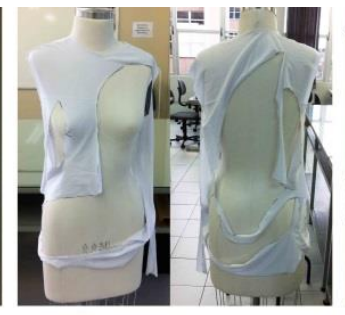

Etapa 2: Cortar as peças

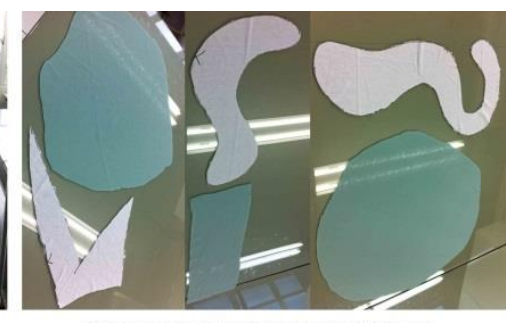

Etapa 3: Medir o diâmetro das formas e

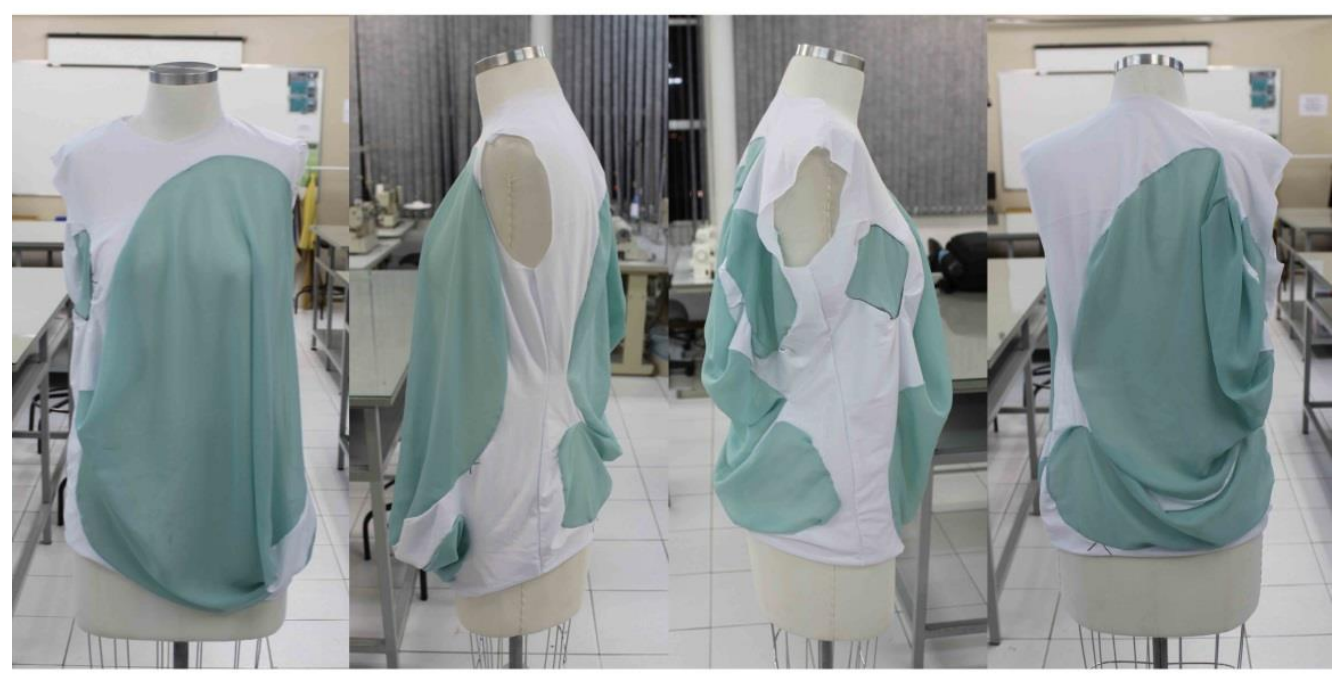

Etapa 4: Aplicar as novas formas no lugar das correspondentes

Fonte: Elaborado pela autora. 
Para o trabalho final da disciplina foi confeccionada uma bolsa em tecido de lã batida (100\% WO) com aplicações de pregas na lateral e dois tipos de origami, seguindo os exercícios propostos por Singer (2013). O resultado pode ser visualizado na figura 6.

Figura 6 - Trabalho final desenvolvido a partir da metodologia de Singer (2013)

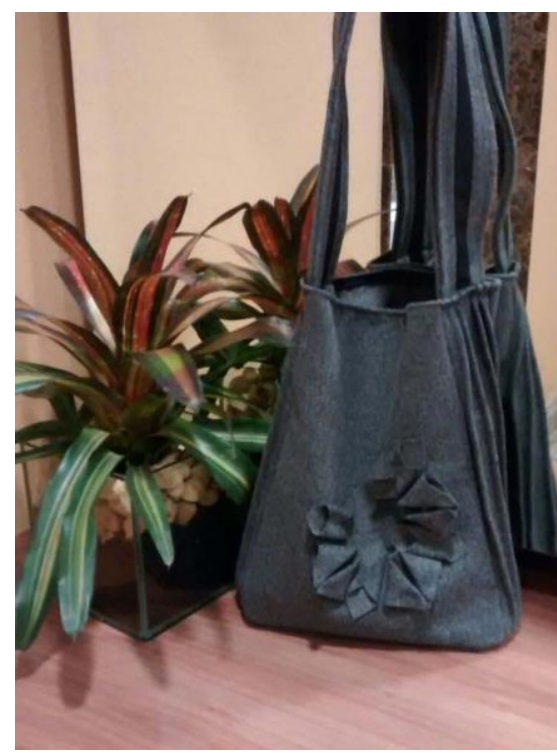

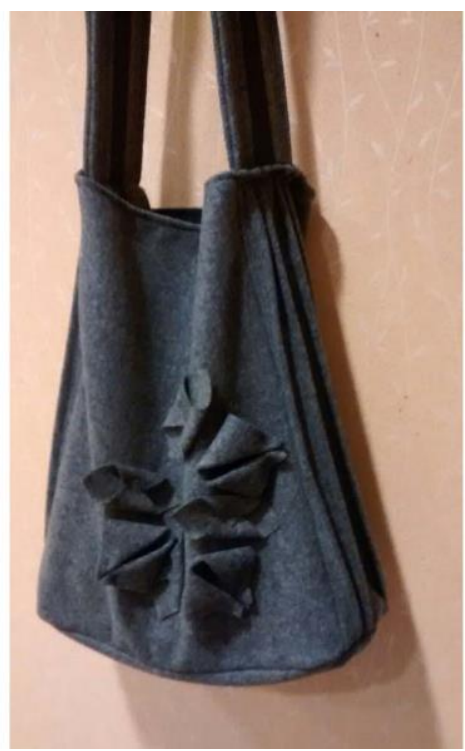

Fonte: Elaborado pela autora.

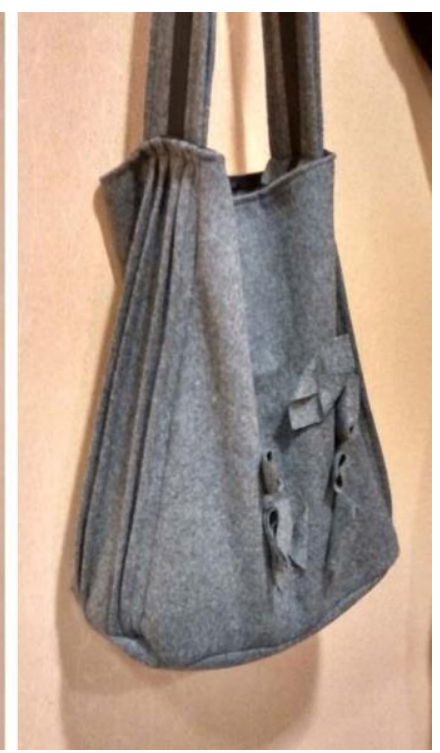

\section{Manipulação e matéria-prima}

Osório (2007) considera "características de moda" as alterações realizadas na estrutura anatômica do corpo, podendo aumentar e diminuir a dimensão corporal ou também adicionar volume em partes específicas de um molde. Já para Perazzo e Valença (2002, apud Souza, 2006) a forma é a totalidade do objeto e não o seu contorno, unida com a percepção do usuário, resultando em diversos discernimentos, atribuindo um caráter múltiplo.

Saltzman (2004) reforça os conceitos de Osório (2007) e Perazzo e Valença (2002, apud Souza, 2006), e afirma que as etapas do processo construtivo (pregas, franzidos, recortes, viés, estampas, cores, texturas) enfatizam partes específicas do corpo e da peça, influenciando e ajudando a gerar volumes e sustentações diferenciais. Nas peças tridimensionais, os materiais devem ser considerados na hora da confecção, posto que possam sofrer alterações na elasticidade, no encolhimento ou na folga (MARINHO E ROCHA, 2009). 
Para se inquirir a linguagem visual de uma peça é necessário levar em consideração a organização também visual de elementos como: formato, tamanho, cor e textura. A forma/volume gerado em uma peça ressalta a importância da linguagem e mensagem transmitida ao usuário. Necessita-se também identificar se o usuário pensa de forma tridimensional ou bidimensional, pois este fator irá alterar na interpretação do produto (WONG, 2001).

Roberts (2013) acredita que ideias criativas vão muito mais longe quando estão "livres" de um compromisso e, consequentemente acabam sendo utilizadas das mais diversas formas e dos jeitos mais inusitados. Isso parte do conceito "What If?" tradução livre para o português "E se?" - que consiste na liberdade e nos questionamentos durante o processo criativo. Exemplos: E se eu realizasse um corte diferente na cava e adicionasse um tecido com outra textura gerando um volume diferenciado?

Relacionado à criatividade e a experimentos na era digital, Kleon (2012) acredita nos preceitos do "faça você mesmo e se possível com as próprias mãos". Durante o andamento é necessário ter dois espaços, um digital e um manual, começando assim com as "manualidades" e, após o projeto estar bem desenvolvido partir para o computacional. Kleon (2012) afirma que o computador limita os processos criativos, fazendo com que queiramos editar o que nem foi criado ainda.

A ergonomia segundo Iida (2003, pg. 39) é “uma ciência experimental, cujas conclusões dependem de experimentos realizados com seres humanos". É possível utilizar esse conceito para as etapas do processo criativo/construtivo/experimental, onde o usuário e sua percepção devem ser levados em consideração durante todas as fases.

A mistura de técnicas como drafiting e draping, e de conceitos trazidos da ergonomia para o desenvolvimento criativo, pode ser considerado interdisciplinaridade. Para Amarante (1997) a interdisciplinaridade no design é fundamental para que haja a união de áreas distintas e troca de conhecimento pessoal e profissional. Couto (1999) concorda e afirma que a interdisciplinaridade é a essência do Design:

O Design se constrói e reconstrói permanentemente, unindo conhecimentos científicos, empíricos e intuitivos, e impregnando-os na atividade de produzir projetos e de teorizar sobre a atividade de configurar objetos. A análise do movimento de visitação permitiu corroborar a noção de que o Design, interdisciplinar por natureza, mantém viva esta característica nas mais variadas esferas em que é desdobrado (COUTO, 1999, p. 86). 
É interessante notar que durante o desenvolvimento do vestuário seja realizada a interdisciplinaridade, repensando no modo de criar e transformando todo o processo em um único resultado. Utilizar mais de uma técnica quando na mesma peça, ou realizar a mesma técnica em diferentes tecidos, confeccionando assim o próprio acervo de experimentos.

\section{Considerações Finais}

Como mencionado anteriormente, a técnica de drafiting tem como foco da modelagem plana através de medidas pré-estabelecidas, e o draping considera a manipulação do substrato têxtil utilizado. As duas técnicas têm princípios diferentes e podem resultar em objetos iguais ou completamente distintos. O objetivo do presente trabalho foi concluído no que propõe a manipulação de formas e tecidos, utilizando a união das duas técnicas e de diferentes substratos têxteis.

Analisando as técnicas testadas durante as aulas é possível identificar que a prática de Singer (2013) tem como embasamento origamis em tecido. Mostrando-se muito útil quando é necessário aplicar algum detalhe diferencial na peça, assim como os outros exercícios de seu livro. Já os testes a partir da metodologia de Rutzky e Palmer (2011), se tornam uma boa opção de estamparia volumétrica. As formas podem ser geradas a partir de pequenos pontos de costura que depois de dobrados e passados da forma correta criam incríveis texturas das mais diferentes formas chapadas em uma única cor.

O segundo experimento realizado a partir de uma junção de técnicas repassadas pela professora Julia Isoppo Picoli se mostrou entre a barreira do comercial e conceitual. Este exercício depende muito do criador e de seu processo criativo para que o resultado tenda mais para um lado ou para o outro. Podem-se gerar pregas e texturas modestas, transformando a peça focada no comércio ou também é interessante brincar com os volumes e preenchimentos desenvolvendo um produto conceito.

Os experimentos de Roberts (2013) resultam em formas desiguais, com volumes inusitados e movimentos únicos. Provavelmente é a técnica que mais se assemelha à moulage, devido ao fato de livre experimentação sem medo de errar. O melhor deste método é que mesmo que o criador considere o resultado muito conceitual, o produto 
acaba se tornando totalmente mutável, podendo ser alterado até mesmo pelo próprio usuário. O processo criativo a partir do método de Roberts (2013) segue os preceitos de Kleon (2012), onde a principal chave são os testes e os processos manuais.

É importante ressaltar que durante o processo de criação seja levado em consideração o fator da interdisciplinaridade, tendo como essência a mistura de técnicas. A indústria necessita de mais criadores que saibam se reinventar, utilizando não só um pedaço de papel ou uma tela de computador, mas a partir de testes e manipulações dos substratos têxteis. São as experimentações, as misturas, os testes e as invenções que geram inovações para a área da moda e do design buscando um processo de mudança constante.

\section{Artigo recebido em Julho de 2015. Aprovado em Setembro de 2015 DOI:http://dx.doi.org/105965/1982615x08172016359}

\section{REFERÊNCIAS}

AMARANTE, Gustavo Bomfim. Fundamentos de uma teoria transdisciplinar do design: morfologia dos objetos de uso e sistemas de comunicação. Estudos em Design, v.5, n.2, p.27-41. Rio de Janeiro: dez. 1997.

COUTO, Rita Maria de Souza. Contribuição para um design interdisciplinar. Estudos em Design, v.7, n.1, p.79-90. Rio de Janeiro: jan.-abr., 1999.

FERREIA, Cainã Improta. Virar do Avesso. São Paulo: Universidade Anhembi Morumbi, 2013.

HEINRICH, Daiane Pletsch. Modelagem e técnicas de interpretação para confecção industrial. Novo Hamburgo: Editora Feevale, 2007.

IIDA, Itiro. Ergonomia: projeto e produção. 2. ed. São Paulo: E. Blucher, 2008.

KLEON, Austin. Roube como um artista - 10 dias sobre criatividade. Nova Iorque: Rocco, 2013.

MARINHO, Nathilucy do Nascimento; ROCHA, Maria Alice Vasconcelos. Um estudo antropométrico auxiliar: adequação de manequins ao corpo da mulher brasileira. Pernambuco: III Encontro de Ensino, Pesquisa e Extensão da Faculdade SENAC, 2009. 
OSÓRIO, Ligia. Modelagem - organização e técnicas de interpretação. Caxias do sul: EDUCS, 2007.

ROBERTS, Julian. Free Cutting. Disponível em: < http://www.julianand.com/ >. Acesso 7 ago 2015.

RUTZKY, Jeffrey; PALMER, Chris K.. Shadowfolds - Surprisingly Easy-to-make geometric designs in fabrics. USA: Kodansha USA, 2011.

SALTZMAN, Andréa. El cuerpo diseñado: sobre la forma em el proyeto de la vestimenta. Buenos Aires: Paidós, 2004.

SILVEIRA. Icléia. Usabilidade do Vestuário: Fatores Técnicos/Funcionais. Modapalavra e-periódico: Ano 1, n.1, jan-jul 2008.

SINGER, Ruth. Fabric Manipulation - 150 creative sewing techniques. USA: David \& Charles, 2013.

SOUZA, Patrícia de Mello. A modelagem tridimensional como implemento do processo de desenvolvimento do produto de moda. Bauru: UNESP, 2006. Disponível em: <https://www.faac.unesp.br/Home/Pos-Graduacao/Desig n/Dissertacoes/patricia.pdf $>$. Acesso 30 jul 2015.

WONG, Wucius. Princípios de forma e desenho. São Paulo: Martins Fontes, 2001. 